\title{
Surface-wave tomography for mineral exploration: a successful combination of passive and active data (Siilinjärvi phosphorus mine, Finland)
}

\author{
Chiara Colombero ${ }^{1}$, Myrto Papadopoulou ${ }^{1}$, Tuomas Kauti ${ }^{2}$, Pietari Skyttä2 ${ }^{2}$ Emilia Koivisto ${ }^{3}$, Mikko
}

5 Savolainen $^{4}$ and Laura Valentina Socco ${ }^{1}$

${ }^{1}$ Department of Environment, Land and Infrastructure Engineering, Politecnico di Torino, Torino, 10129, Italy

${ }^{2}$ Department of Geography and Geology, FI-20014 University of Turku, Finland

${ }^{3}$ Department of Geosciences and Geography, University of Helsinki, Helsinki, FI-00014, Finland

${ }^{4}$ Yara Suomi Oy, Siilinjärvi, Finland

10 Correspondence to: Chiara Colombero (chiara.colombero@ polito.it)

\begin{abstract}
Surface wave (SW) methods are ideal candidates for an effective and sustainable development of seismic exploration, but still remain under-exploited in hard rock sites. We present a successful application of active and passive surface wave tomography for the characterization of the southern continuation of the Siilinjärvi phosphate deposit (Finland). A semi-automatic workflow for the extraction of the path-average dispersion curves (DCs) from ambient seismic noise data is

15 proposed, including identification of time windows with strong coherent SW signal, azimuth analysis and two-station method for DC picking. DCs retrieved from passive data are compared with active SW tomography results recently obtained at the site. Passive data are found to carry information at longer wavelengths, thus extending the investigation depth. Active and passive DCs are consequently inverted together to retrieve a deep pseudo-3D shear-wave velocity model for the site, with improved resolution. The seismic results are compared with the latest available geological models to both validate the proposed

20 workflow and improve the interpretation of the geometry, extent and contacts of the mineralization. Important large-scale geological boundaries and structural discontinuities are recognized from the results, demonstrating the effectiveness and advantages of the methods for mineral exploration perspectives.
\end{abstract}

\section{Introduction}

Challenges in mineral exploration are growing since current targets are typically located at increasing depths (Decrée and

25 Robb, 2019) and within the proximity of existing mine infrastructures, where noise, accessibility and environmental impact issues exist. To be successful, modern mineral exploration methods should progress technologically to ensure improved efficiency, economic viability and environmental sustainability. In this framework, high resolution seismic velocity models can assist the construction of high quality, reliable geological models comprising information about the composition and structural geometry of the bedrock, which are both crucial for successful exploration. However, mineral exploration sites are typically characterized by intricate hard rock geology, inherently related to complex wave propagation and challenging seismic 
https://doi.org/10.5194/se-2021-121

Preprint. Discussion started: 1 October 2021

(c) Author(s) 2021. CC BY 4.0 License.

(c) (i)

prospection (Eaton et al., 2003), both exploiting body waves (BWs) and surface waves (SWs). The sensitivity of SWs to nearsurface properties and lateral variations, their high energy in seismic recordings and lower attenuation with respect to BWs, as well as the high velocity field expected at hard rock sites make them ideal candidates for high-resolution deep mineral exploration. In both active and passive SW tomography (SWT), dispersion curves (DCs) can be retrieved between pairs of receivers and then inverted in a tomographic approach to estimate 2D/3D (depending on the receiver geometry) shear-wave velocity distributions at several grid points (Kennett and Yoshizawa, 2002). Depending on the spatial and wavelength coverage and the superposition between different receiver-pair paths, high resolution can be achieved (Yin et al., 2016). SWT is even more attractive with the use of passive data, since ambient seismic noise is typically dominated by these waves. The SW signal contained in ambient noise is usually of lower frequency (i.e. longer wavelength), with respect to the one produced by the

40 active-seismic sources of exploration, potentially meaning higher investigation depths.

However, the use of SWs remains under-exploited in hard rock sites, while in other fields of applications, such as global seismology, passive SWT, exploiting ambient seismic noise or earthquakes, is widely used to map the laterally varying structure of the Earth's crust and mantle (e.g. Ritzwoller and Levshin, 1998; Kennett and Yoshizawa, 2002; Shapiro et al., 2005; Sabra et al., 2005).

45 Compared to active SWT, the extraction of high-quality DCs from passive-source data is not straightforward. Indeed, the direction of propagation of SW with respect to the receivers' location is unknown and likely variable over time. To ensure that useful SW information is contained in the data, the field measurements are usually performed over long time periods, leading to large datasets which are difficult to process, especially when the processing scheme is not automated. Finally, ambient noise usually lacks high-frequency SW information, impeding the retrieval of accurate velocity estimates at shallow depths.

50 In the field of natural-resource exploration, SWT is consequently mainly used for the characterization of deep geothermal reservoirs (e.g. Lehujeur et al., 2017; Martins et al., 2020; Planès et al., 2020). Promising examples, though, have shown its potential to be used as a low-cost and environmentally friendly investigation method, also in hydrocarbon (e.g. Bussat and Kugler, 2009) and mineral (Hollis et al., 2018; Lynch et al., 2019; Da Col et al., 2020) exploration.

Here, we present a successful integration of active and passive SWT for the characterization of the southern tail of the

55 Siilinjärvi phosphate deposit (Laukansalo, Siilinjärvi, Finland) where a new open pit mine is planned to be opened in 15 years. Data acquisition, processing and methodological implementation were carried out within H2020 Smart Exploration project (grant agreement no. 775971), to envisage innovative and environmentally friendly methods for the sustainable exploration of mineral resources. We designed and tested a semi-automatic workflow for the extraction of coherent SW signal from ambient seismic noise recordings, azimuth analysis and picking of DCs for the tomographic inversion. Active SWT results from the

60 same area of investigation, down to a depth of approximately $210 \mathrm{~m}$, display a low-velocity area compatible with the presence of the carbonatite complex and high-velocity anomalies matching the position of known diabase dykes (Da Col et al., 2020). In this work, we exploit the lower frequencies contained within the passive data to improve the azimuthal coverage and investigation depth. Active and passive DCs are then inverted together to retrieve a high-resolution shear-wave velocity $\left(\mathrm{V}_{\mathrm{S}}\right)$ model down to a depth of $480 \mathrm{~m}$. We finally compare the results with the overall structural framework of the site, the latest 
https://doi.org/10.5194/se-2021-121

Preprint. Discussion started: 1 October 2021

(c) Author(s) 2021. CC BY 4.0 License.

\section{(c) (1)}

65 geological models of the owning company (Yara) and the available diamond drill holes (DDH), typically extending to the depth of $200 \mathrm{~m}$ below the ground level. The results of this investigation comprise: i) improved understanding of the structural patterns of the site, including the contacts of the mineralization, ii) validation of surface wave tomography (SWT) as a reliable, effective and sustainable tool for mineral exploration, and iii) guidelines for future mine planning at the site.

\section{Test site and passive seismic data set}

70 Siilinjärvi phosphorus mine, located in the municipality of Siilinjärvi, $20 \mathrm{~km}$ north of the city of Kuopio (Finland, Fig. 1a), is the only operating mine producing phosphorus within the EU. The phosphorus-bearing mineral is apatite, currently extracted from two open pits exploiting one of the oldest carbonatites on Earth (2.61 Ga; e.g. Tichomirowa et al., 2006; O'Brien et al., 2015). The ore occurs as a sub-vertically dipping, N-S trending sheeted body measuring approximately $1 \mathrm{~km}$ in width and 15 $\mathrm{km}$ in length (Fig. 1b), continuing south of the current exploitation area (Fig. 1c). The ore body is known to extend down to

$75800 \mathrm{~m}$ depth (Malehmir et al., 2017).

The Siilinjärvi deposit is comprised of carbonatite-glimmerite rocks intruded into Archaean granitic and gneissic host rocks. Alkali metasomatised fenite halo encircles the carbonatite-glimmerite ore zone. Evenly spaced, predominantly NW-SE to N$\mathrm{S}$ striking diabase (i.e. waste rock) dykes crosscut the entire ore body. The thickness of the dykes varies within a range of a few centimetres to several tens of meters (Puustinen, 1971), and most of the known dykes show steep dips, but a significant group of moderately to gently dipping dykes is also known to exist (Mattsson et al., 2019). The dykes intersect each another creating a complex structural pattern, which is later disrupted by N-S trending shearing along the ore boundaries and by Proterozoic (1.89 Ga) dioritic-tonalitic intrusion in the SW border of the deposit (e.g. Lukkarinen, 2008; Fig. 1b). For future mine planning, beside the more complete characterization of the intricate geo-structural setting, further identification and location of sub-horizontally oriented diabase dykes at depth would be crucial. As their locations and extent can`t be reliably predicted based on surface and borehole geological observations, geophysical methods are needed to aid the mapping. Active and passive seismic data were acquired at Siilinjärvi phosphorus mine in 2018, with a 3D array of randomly-distributed stations (Fig. 1c). The seismic array consisted of 578 vertical geophones $(10 \mathrm{~Hz})$ connected to wireless stations, and almost continuously recorded for 13 days (September 24 - October 6). Passive data from all stations were recorded at $500 \mathrm{~Hz}$ and stored in 1-minute segy files. The deployment design was chosen to respect site and instrumentation logistical constraints and to optimize subsurface illumination (in terms of wavelength and azimuth coverage) in the areas of interest (Da Col et al., 2020). Beside the seismic reflection lines (SM1 to SM3 in Fig. 1b), remaining seismic stations were deployed in three main areas, including the main pit to the north, the gypsum pile located SW, and the southern forest area (Fig. 1c). The latter (Laukansalo, Siilinjärvi) is of crucial importance for future mining activities, since it is known that the mineralization extends to the south from the current main pit. In this area, the 3D random array included 273 stations (in red in Fig. 1c and Fig. 1d) covering 
https://doi.org/10.5194/se-2021-121

Preprint. Discussion started: 1 October 2021

(c) Author(s) 2021. CC BY 4.0 License.

(c) (i)

to increase depth and resolution of the shear-wave velocity model retrieved for the southern continuation of the mineralization by active SWT (Da Col et al., 2020).

\section{Passive seismic tomography workflow}

The processing workflow adopted for passive SWT is summarized in Fig. 2. Before the tomographic inversion, a two-step semi-automatic workflow was designed to extract the path-average DCs from the passive data.

In the pre-processing step (I in Fig. 2), each 1-minute segy file is windowed in 2-s segments. On each window, the Frequency Domain Beam Forming (FDBF) method (Zywicki, 1999) is applied to retrieve frequency-wavenumber ( $\left.-\mathrm{k}_{\mathrm{x}}, \mathrm{k}_{\mathrm{y}}\right)$ power spectral density functions, used to identify dispersive events in the recordings and their direction of propagation. The result is a 3D matrix having $\mathrm{k}_{\mathrm{x}}-\mathrm{k}_{\mathrm{y}}$ spectra as planes at the different investigated frequencies (3-20 Hz). This frequency band was chosen

105 to lower the frequency content retrieved from active DCs, generally in the range 7-48 Hz (Da Col et al., 2020). The position of the spectral maximum in each $\mathrm{k}_{\mathrm{x}}-\mathrm{k}_{\mathrm{y}}$ plane provides wavenumbers and azimuth of the dominant SWs propagating at that frequency during the 2-s window. Once the wavenumber modulus $|\mathrm{k}|$ is retrieved from $\mathrm{k}_{\mathrm{x}}$ and $\mathrm{k}_{\mathrm{y}}$ values, the phase-velocity $\left(\mathrm{V}_{\mathrm{R}}\right)$ of the $\mathrm{DC}$ is computed following:

$\mathrm{V}_{\mathrm{R}}=\frac{2 \pi \mathrm{f}}{|\mathrm{k}|}$

110 where $|\mathrm{k}|$, is simply:

$$
|\mathrm{k}|=\sqrt{\mathrm{k}_{\mathrm{x}}^{2}+\mathrm{k}_{\mathrm{y}}^{2}}
$$

Further pre-processing steps are summarized in Fig. 3. The DC retrieved from the FDBF method is compared with a reference dispersion region (Fig. 3a), defined on the basis of the velocity ranges of active dispersion curves at the lowest frequencies. If a significant number of DC points are located within the dispersion region ( $>70 \%)$, data quality is considered sufficient to

115 continue the computations, otherwise, the time window is rejected. For the high-quality time windows, the maxima of the $\mathrm{k}_{\mathrm{x}}{ }^{-}$ $\mathrm{k}_{\mathrm{y}}$ planes are automatically picked (Fig. 3b). For an automatic random selection of peaks, the azimuth is computed based on its location in the related $k_{x}-k_{y}$ plane (Fig. $3 d$ to $3 i$ ). If there is a dominant azimuth, i.e. consistent among the different frequencies (Fig. 3c), the SW event is considered coherent and the time window is stored in a folder associated to that azimuth value. This pre-processing procedure is automatically repeated for all the available records. Fig. 4 shows the number of 2-s time windows containing strong and coherent SW signal, and the related azimuth distribution, retrieved from the preprocessing analyses. Approximately $7.6 \%$ of the recorded 2-s windows showed strong SW signal (Fig. 4a). To be consistent with the $\mathrm{k}_{\mathrm{x}}-\mathrm{k}_{\mathrm{y}}$ plane orientation, the azimuth distribution is shown in the reference system of Fig. $1 \mathrm{~d}$. Nearly $8000 \mathrm{SW}$ events originated at an azimuth around $219^{\circ}$. More in general, a first cluster of events is located between $200^{\circ}$ and $240^{\circ}$, probably related to the workshop activities located towards W-SW, where industrial machineries are produced and tested (Fig. 1c). A 
https://doi.org/10.5194/se-2021-121

Preprint. Discussion started: 1 October 2021

(c) Author(s) 2021. CC BY 4.0 License.

\section{(c) (1)}

125 second cluster of events is centred around $50^{\circ}$, likely related to the factory area located to the NE of the forest, where apatite concentrate is processed on site to produce phosphoric acid and fertilizers (Fig. 1c).

In the second processing step (II in Fig. 2), for each azimuth (Fig. 4b), receiver pairs aligned along this direction, with a tolerance of $1^{\circ}$, are chosen randomly to maximize path length and consequently wavelength distribution (Da Col et al., 2020). A modified version of the two-station method (as implemented by Yao et al., 2006) is applied to each receiver pair (e.g. Fig.

130 5a). The receiver traces are cross-correlated frequency by frequency to extract cross-multiplication matrices. This procedure is repeated for the same receiver pair in all the available time windows having the same dominant azimuth. Individual crossmultiplication matrices are then stacked to increase the signal-to-noise ratio. DCs are automatically extracted as the amplitude maxima of the stacked cross-multiplication matrices (Fig. 5b), using the reference dispersion region of active data (Da Col et al., 2020) to guide the picking at the highest frequencies (>10 Hz).

135 The comparisons between active and passive DCs for the same receiver pairs (e.g. Fig. 5c) showed matching phase-velocity trend and values in the overlapping frequency/wavelength range. The global passive DC dataset (1025 curves) retrieved from the picking of the stacked cross-multiplication matrices is shown in Fig. 6 in comparison with the active DCs (433 curves; Da Col et al., 2020). The curves from passive data are generally characterized by longer wavelengths (Fig. 6b), thus enlarging the depth of investigation. The maximum wavelength of the passive DCs (approximately $1200 \mathrm{~m}$ ) is nearly double the one of the

140 active curves, even though the frequency content in the passive DCs was not significantly lower than the frequencies of the active curves (Fig. 6a). Thanks to the high seismic velocities characterizing the site, even the few additional lower frequency components present in some of the passive curves resulted in significantly large wavelength increases. The two DC data set were therefore merged to improve the invesion results.

The distribution of the path length and azimuths of all the DCs is shown in Fig. 7. Although we observed peaks in the estimated

145 azimuths around $200^{\circ}-240^{\circ}$ and $42^{\circ}-60^{\circ}$ (Fig. 4b) for the passive data, this did not translate to corresponding peaks in the global DC azimuth coverage. Instead, the distribution of DC azimuths is rather homogeneous, apart from a peak in the $150^{\circ}$ and $330^{\circ}$ direction. This was due to the fact that the cross-correlation matrices, computed for the same receiver pair and different time windows, were stacked, and only one DC was extracted for each receiver pair. Moreover, due to the random geometry of the receivers, several receiver pairs with different path lengths existed at the same azimuth (Fig. 7a) and, therefore,

150 a wide range of path lengths was included in the DC set.

The spatial coverage obtained by adding the passive DCs to the active dataset is shown for different depth ranges (assuming a pseudodepth of investigation = half wavelength). DC coverage is dense in the whole forest area and wavelengths and apparent phase velocities show consistent lateral variability at each wavelength. In the active data only, coverage was lower and limited to a depth of approximately $210 \mathrm{~m}$ (Da Col et al., 2020), while acceptable coverage is now retrieved until a depth of 155 approximately $400-500 \mathrm{~m}$.

For the tomographic inversion of the merged data set (III in Fig. 2), the same approach applied to active DCs was followed to retrieve a pseudo three-dimensional shear-wave velocity $\left(\mathrm{V}_{\mathrm{S}}\right)$ model, as described in Boiero (2009). 1D profiles beneath grid points are estimated using damped weighted least square inversion. Horizontal and vertical constraints between neighbouring 
https://doi.org/10.5194/se-2021-121

Preprint. Discussion started: 1 October 2021

(c) Author(s) 2021. CC BY 4.0 License.

(c) (i)

models are set in the regularization matrix to connect $V_{S}$ and thickness information from one model to the surrounding ones.

For the spatial discretization, we assumed 420 uniformly distributed grid points, at $44 \mathrm{~m}$ from each other. After testing different vertical-discretization dimensions, we concluded that the best DC fitting was achieved assuming 7 layers, reaching a maximum depth of $480 \mathrm{~m}$. The adopted initial model is reported in Table 1. A lateral $V_{S}$ constraint of $150 \mathrm{~m} / \mathrm{s}$ for the first four layers and of $500 \mathrm{~m} / \mathrm{s}$ for layers 5-7 was imposed. These were found to be the strongest constraints which did not increase the inversion misfit.

\section{Results}

The final $V_{S}$ model, obtained after 12 iterations, is shown in Fig. 9 as slices at different depths. In the shallow subsurface (30 m, Fig. 9a), low velocity values $(2000-2800 \mathrm{~m} / \mathrm{s})$ are almost homogeneously displayed. Deeper, down to $240 \mathrm{~m}$, the model presents a clear mapping of the low-velocity values, which have been previously attributed to the presence of the carbonatites (Da Col et al., 2020). In the same slices, the results highlight several local high-velocity anomalies, which have been earlier interpreted, depending on their location, as the intrusions of diabase dykes within the Siilinjärvi deposit or as the host rock (Fig. $9 \mathrm{~b}$ to d). The layers between $330 \mathrm{~m}$ and $480 \mathrm{~m}$ (Fig. 9e to g) present a greater extent of high velocity zones (3300-4000 $\mathrm{m} / \mathrm{s}$ ) and lower lateral variability.

The histogram of Fig. 10a shows the misfit between the experimental and theoretical (computed for the inverted model) DC points. The Normalized Root Mean Square Deviation of the DCs along the analyzed two-station paths is shown in Fig. 10b.

175 The misfit is lower than $12.5 \%$ for more than $75 \%$ of the data points, and there are no zones over the investigated area with concentration of high misfits.

To evaluate the resolution of the final model, a checkerboard test was performed. The initial model velocities (Table 1) were perturbed positively and negatively ( $\pm 8 \%$ ) according to the regular pattern of Fig. 11a (squares of $200 \times 200 \mathrm{~m}$ ). The $\mathrm{V}_{\mathrm{S}}$ perturbations obtained after the inversion are presented in Fig. 11b. Velocity perturbations at depths 30-330 m are well reconstructed, apart from the south-western portion of the slice at 90-m depth (red box in Fig. 11). At depths 330-480 m, the quality of the inverted checkerboard model reduces, especially at $330 \mathrm{~m}$ depth, where the perturbations in the southern portion of the model appear smoothened (blue box in Fig. 11). Nevertheless, the dimensions of the rest of the perturbation blocks in all the other layers are clearly identified in the inverted checkerboard model. Therefore, it can be concluded that the resolution of the experimentally retrieved $V_{S}$ model of Fig. 9 equals, at least, the size of the perturbation blocks of Fig. 11, except for the two zones indicated by the coloured boxes.

\section{Discussion}

The combined use of active and passive data led to the reconstruction of a deeper $\mathrm{V}_{\mathrm{S}}$ model for the area south of the current Siilinjärvi phosphorus mine where a new open pit is planned. Compared to active SWT only, the final model (Fig. 9) 
https://doi.org/10.5194/se-2021-121

Preprint. Discussion started: 1 October 2021

(c) Author(s) 2021. CC BY 4.0 License.

(c) (i)

highlighted more continuous features which geological interpretation may offer a valuable support for the characterization of

the mineralization and future mining plans.

The carbonatite-glimmerite bodies show generally low-velocity signatures as already found in Da Col et al. (2020), but the final velocity distribution now better highlights the general NNE-SSW orientation of the mineralization down to the 240-m depth (Fig. 12b to Fi. 12d). Also the fenite bodies are found to be associated with low-velocity signatures, while surrounding granite and gneiss show the highest $V_{S}$ values at shallow depths $(<240 \mathrm{~m})$. No sharp velocity contacts are depicted at the boundaries of the mineralization, but relatively clear arrays of NNE-SSW discontinuities coincide with diabase dykes and shear zones as modelled by Yara (Fig. 12a) and can be used to delineate the margins of the mineralization (I in Fig. 12c). In particular, the western contact is visible at all depths, and it is more distinct than the eastern margin. The contrasting character of the margins is in line with the observations on DDH data, where the eastern contact is found to be gradational and defined by alternating layers of carbonatite-glimmerite, fenite and tonalite. In the eastern area of investigation, the NNE-SSW discontinuities and transitions in the seismic velocity signatures can be used to improve the delineation of the contacts between fenite and granite-gneiss (IV). Some structural embayments along the fenite-granite gneiss contact are possible, as highlighted by the different dash pattern along line IV at the depth of $150 \mathrm{~m}$ (Fig. 12c), and such geometry is compatible with the overall irregular thickness of the fenite within the ground surface level geological maps (Fig. 1b). A sharp increase in velocity is seen from the depth of $240 \mathrm{~m}$ downwards, but with no direct linkage to known geological features. The increasing velocities are likely consistent with a reduction in weathering from the shallow subsurface downwards. However, this also matches the fabric of stronger reflectivity segments on the 2D reflection seismic profiles (SM1 and SM2 in Fig. 1c), possibly originating from contacts to diabase dykes.

In the model slices 90-240 m, discontinuous higher-velocity areas within the mineralization, and to a lesser degree in fenite, loosely define a structural network that we infer to represent diabase dykes (II, III, V and VI). In particular, feature II does not directly correlate with any known diabase dyke set, but could result from the interplay of different dyke sets, comprising also the strictly horizontal dykes presently included in the gently ESE-dipping set (orange in Fig. 12b). Feature III may correlate with the sub-vertical NNW-SSE trending dyke set (magenta in Fig. 12b). The orientation of thin diabase dykes found in some DDH is compatible with V and VI at 240-m depth, as well as with the larger dykes bounding the mineralization.

At deeper levels, the NNE-SSW trending western margin of the high-velocity material remains the most visible feature, in

215 agreement with the regional trend and the dominant population of diabase dykes, while no internal structures can be recognized in the mineralization from the seismic results. A parallel (NNE-SSW) but less distinct seismic "low" coincides with the fenite bounding the mineralization to the $\mathrm{E}$.

In general, decametric geo-structural features, with a size compatible with the checkerboard perturbations of Fig. 11, are clearly observable in the SWT results. Smaller-scale individual dykes and other local geological features shown by DDH data and observations in the Siilinjärvi main pit, further in the north, are below the expected resolution. 
https://doi.org/10.5194/se-2021-121

Preprint. Discussion started: 1 October 2021

(c) Author(s) 2021. CC BY 4.0 License.

(c) (i)

\section{Conclusion}

The application of combined active and passive SWT provided a high-resolution deep seismic velocity model for the southern continuation of the Siilinjärvi phosphate deposit, on which new mining activities are planned for after 2035. We proposed a semi-automatic workflow for the extraction of the path-average DCs from ambient noise data recorded on site in 2018. The pre-processing steps allow the extraction of the time windows containing sufficient SW energy, minimizing the time and computational costs of the subsequent processing steps. The distribution of azimuths provides information about the noise sources and allows for the application of the two-station method, which requires the receivers to be in-line with the source. The method is almost fully automatic, apart from a manual quality control on the picked DCs. However, due to the large size of the data set (almost $800 \mathrm{~GB}$ ), the pre-processing computations required around 3 weeks, running in parallel on a 10-core

230 workstation. Including only the accepted time windows, the data set was downsized to approximately 61.5 GB. The DCs obtained by the proposed workflow are comparable to the ones obtained from active data in the overlapping frequency range, thus supporting the reliability of the results. Moreover, it was shown that passive data contain more information about the deeper subsurface portions, increasing the investigation depth and therefore, opening the possibility of mapping the target at depth. Combined with the active DCs, they provided high resolution SWT results down to 480-m depth. The time required for

235 the two-station processing, stacking and semi-automatic DC picking was approximately 1 week, while the tomographic inversion required approximately 6.5 hours on the same 10-core workstation. The final velocity model was validated through interpretation of the main seismic signatures in comparison with the available geo-structural data. Results confirm the southern extension of the carbonatite-glimmerite deposits, help in constraining the geometry of the mineralization and in unravelling the intricate relationships with the host rocks and the major intruding dikes. This model can be used to guide future drilling

240 efforts for planning the new open pit in the area.

This successful application has proven that the use of passive data within SWT is a promising, cost-effective and sustainable tool for mineral exploration, overcoming the need for active seismic sources.

\section{Code/Data availability}

Code and data were developed and acquired within the EU H2020 project Smart Exploration (grant agreement No. 775971) 245 and may be available by contacting the corresponding author.

\section{Author contribution}

CC and MP worked on SW passive data processing, with coordination and supervision of LVS. TK, PS, EK and MS worked on the geological interpretation of the seismic results. MP and EK contributed to seismic data acquisition. CC wrote the original paper draft, with contributions from all the authors. 
https://doi.org/10.5194/se-2021-121

Preprint. Discussion started: 1 October 2021

(c) Author(s) 2021. CC BY 4.0 License.

(c) (i)

\section{Competing interest}

The authors declare that they have no conflict of interest.

\section{Acknowledgements}

Smart Exploration has received funding from the European Union's Horizon 2020 research and innovation programme under grant agreement No. 775971. We thank Yara Suomi Oy for the access to geological models, and their overall hospitality. The data were acquired using combined seismic equipment of Uppsala University and Geopartner Sp. z.o.o., for which we are thankful. We thank everyone who participated in the survey, especially the Master and Ph.D. students, whose support was vital during the field work, and Federico Da Col, whose work on the active data provided solid bases for the continuation of the study.

\section{References}

Boiero, D.: Surface wave analysis for building shear wave velocity models. PhD Thesis, Politecnico di Torino, Torino, Italy, 2019.

Bussat, S., and Kugler, S.: Recording noise - Estimating shear-wave velocities: Feasibility of offshore ambient-noise surfacewave tomography (answt) on a reservoir scale, SEG Technical Program Expanded Abstracts 2009, 1627-1631, doi: 10.1190/1.3255161, 2009.

265 Da Col, F., Papadopoulou, M., Koivisto, E., Sito, Ł., Savolainen, M., and Socco, L. V.: Application of surface-wave tomography to mineral exploration: A case study from Siilinjärvi, Finland, Geophys. Prospect., 68(1), 254-269, doi: 10.1111/1365-2478.12903, 2020.

Decrée, S., and Robb, L.: Developments in the Continuing Search for New Mineral Deposits, Eos, 100. doi: 10.1029/2019EO128347, 2019.

270 Eaton, D. W., Milkereit, B., and Salisbury, M. H.: Hardrock Seismic Exploration, Society of Exploration Geophysicists, Tulsa, USA, doi: 10.1190/1.9781560802396, 2003.

Hollis, D., McBride, J., Good, D., Arndt, N., Brenguier, F., and Olivier, G.: Use of ambient noise surface wave tomography in mineral resource exploration and evaluation, SEG Technical Program Expanded Abstracts 2018, 1937-1940, 2018.

Kennett, B. L. N., and Yoshizawa, K.: A reappraisal of regional surface wave tomography, Geophys. J. Int., 150(1), 37-44. doi: 10.1046/j.1365-246X.2002.01682.x, 2002.

Lehujeur, M., Vergne, J., Maggi, A., and Schmittbuhl, J.: Ambient noise tomography with non-uniform noise sources and low aperture networks: Case study of deep geothermal reservoirs in northern Alsace, France, Geophys. J. Int., 208(1), 193210. doi: 10.1093/gji/ggw373, 2017. 
https://doi.org/10.5194/se-2021-121

Preprint. Discussion started: 1 October 2021

(c) Author(s) 2021. CC BY 4.0 License.

(c) (i)

Lukkarinen, H.: Pre-Quaternary rocks of the Siilinjärvi and Kuopio map-sheet areas. Geological map of Finland 1:100000. Explanation to the maps of Pre-Quaternary rocks, Sheets 3331 Siilinjärvi and 3242 Kuopio, Espoo, 2008.

Lynch, R., Hollis, D., McBride, J., Arndt, N., Brenguier, F., Mordret, A., Boué, P., Beaupretre, S., Santaguida, F., and Chisolm, D.: Passive seismic ambient noise surface wave tomography applied to two exploration targets in Ontario, Canada, SEG Technical Program Expanded Abstracts 2019, 5390-5392, 2019.

Malehmir, A., Heinonen, S., Dehghannejad, M., Heino, P., Maries, G., Karell, F., Suikkanen, M., and Salo, A.: Landstreamer seismics and physical property measurements in the Siilinjärvi open-pit apatite (phosphate) mine, central Finland. Geophysics, 82(2), B29-B48, doi: 10.1190/geo2016-0443.1, 2017.

Martins, J. E., Weemstra, C., Ruigrok, E., Verdel, A., Jousset, P., and Hersir, G. P.: 3D S-wave velocity imaging of Reykjanes Peninsula high-enthalpy geothermal fields with ambient-noise tomography, J. Volcanol. Geotherm. Res., 391, 106685, doi: 10.1016/j.jvolgeores.2019.106685, 2020.

Mattsson, H. B., Högdahl, K., Carlsson, M., Malehmir, A.: The role of mafic dykes in the petrogenesis of the Archean Siilinjärvi carbonatite complex, east-central Finland, Lithos, 342, 468-479, doi: 10.1016/j.lithos.2019.06.011, 2019.

O’Brien, H., Heilimo, E. and Heino, P.: The Archean Siilinjärvi carbonatite complex, Mineral Deposits of Finland, 327-343, doi: 10.1016/B978-0-12-410438-9.00013-3, 2015.

Planès, T., Obermann, A., Antunes, V., and Lupi, M.: Ambient-noise tomography of the Greater Geneva Basin in a geothermal exploration context, Geophys. J. Int., 220(1), 370-383. doi: 10.1093/gii/ggz457, 2020.

Puustinen, K.: Geology of the Siilinjärvi carbonatite complex, eastern Finland. Geological Survey of Finland, Bulletin de la Commission Géologique de Finlande, 249, 43 pp., 1971.

Ritzwoller, M. H., and Levshin, A. L.: Eurasian surface wave tomography: Group velocities. Journal of Geophysical Research: Solid Earth, 103(B3), 4839-4878, 1998.

Shapiro, N. M., Campillo, M., Stehly, L., and Ritzwoller, M. H.: High-resolution surface-wave tomography from ambient seismic noise, Science, 307(5715), 1615-1618, 2005.

Sabra, K. G., Gerstoft, P., Roux, P., Kuperman, W., and Fehler, M. C.: Surface wave tomography from microseisms in Southern California, Geophys. Res. Lett., 32(14), 2005.

Tichomirowa, M., Grosche, G., Götze, J., Belyatsk, B. V., Savva, E. V., Keller, J., and Todt, W.: The mineral isotope composition of two Precambrian carbonatite complexes from the Kola Alkaline Province-Alteration versus primary magmatic signatures, Lithos, 91, 229-249, 2006.

Yao, H., van der Hilst, R. D., and De Hoop, M. V.: Surface-wave array tomography in SE Tibet from ambient seismic noise and two-station analysis - I. Phase velocity maps, Geophys. J. Int., 166(2), 732-744, doi: 10.1111/j.1365246X.2006.03028.x, 2006.

310 Yin, X., Xu, H., Wang, L., Hu, Y., Shen, C., and Sun, S.: Improving horizontal resolution of high-frequency surface-wave methods using travel-time tomography, J. Appl. Geophys., 126, 42-51, doi: 10.1016/j.jappgeo.2016.01.007, 2016. 
https://doi.org/10.5194/se-2021-121

Preprint. Discussion started: 1 October 2021

(c) Author(s) 2021. CC BY 4.0 License.

Zywicki, D. J.: Advanced signal processing methods applied to engineering analysis of seismic surface waves, PhD Dissertation, Georgia Institute of Technology, Atlanta, USA, 1999.
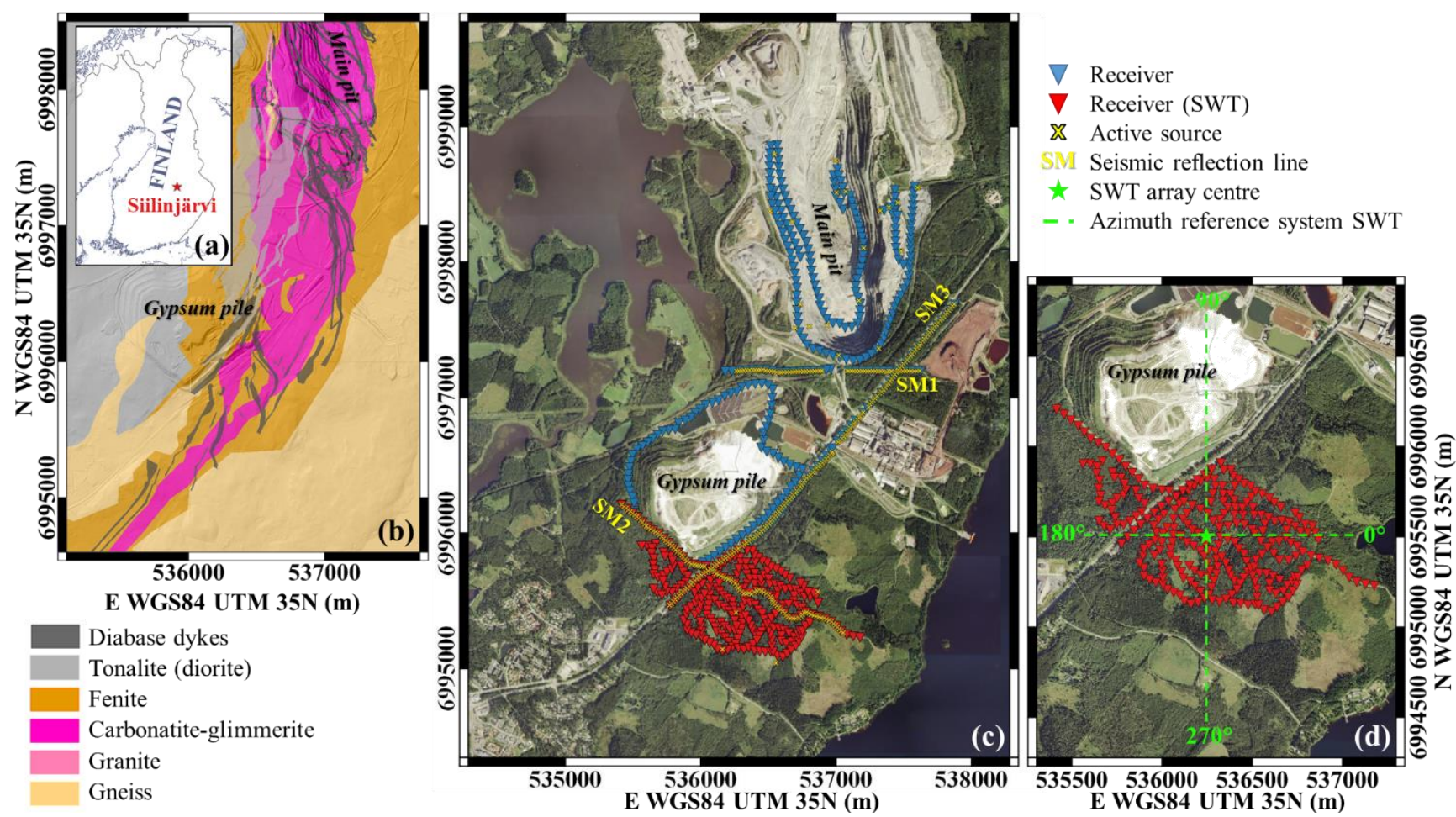

Figure 1: Siilinjärvi mine: (a) geographical location; (b) geological map (Yara); (c) active and passive seismic surveys acquired in 2018; (c) zoom on the passive seismic array in the southern area, used for passive surface-wave tomography (SWT). The reference system for azimuth analysis is highlighted in green. Ortophotos available from QGIS plugin QuickMapServices (Kapsi ortoilmakuva TMS). 

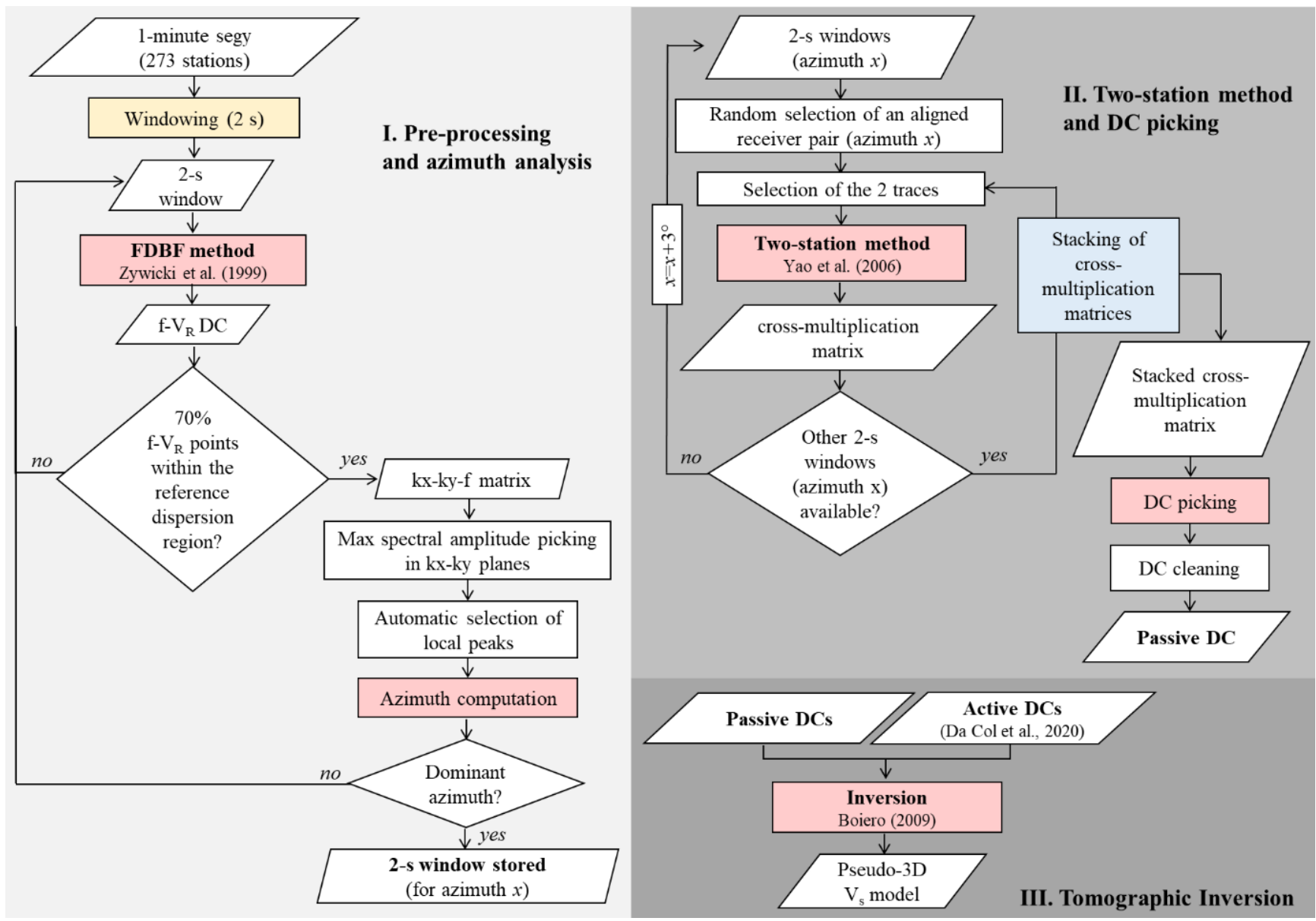

Figure 2: Passive SWT workflow adopted in this study. 
https://doi.org/10.5194/se-2021-121

Preprint. Discussion started: 1 October 2021

(c) Author(s) 2021. CC BY 4.0 License.
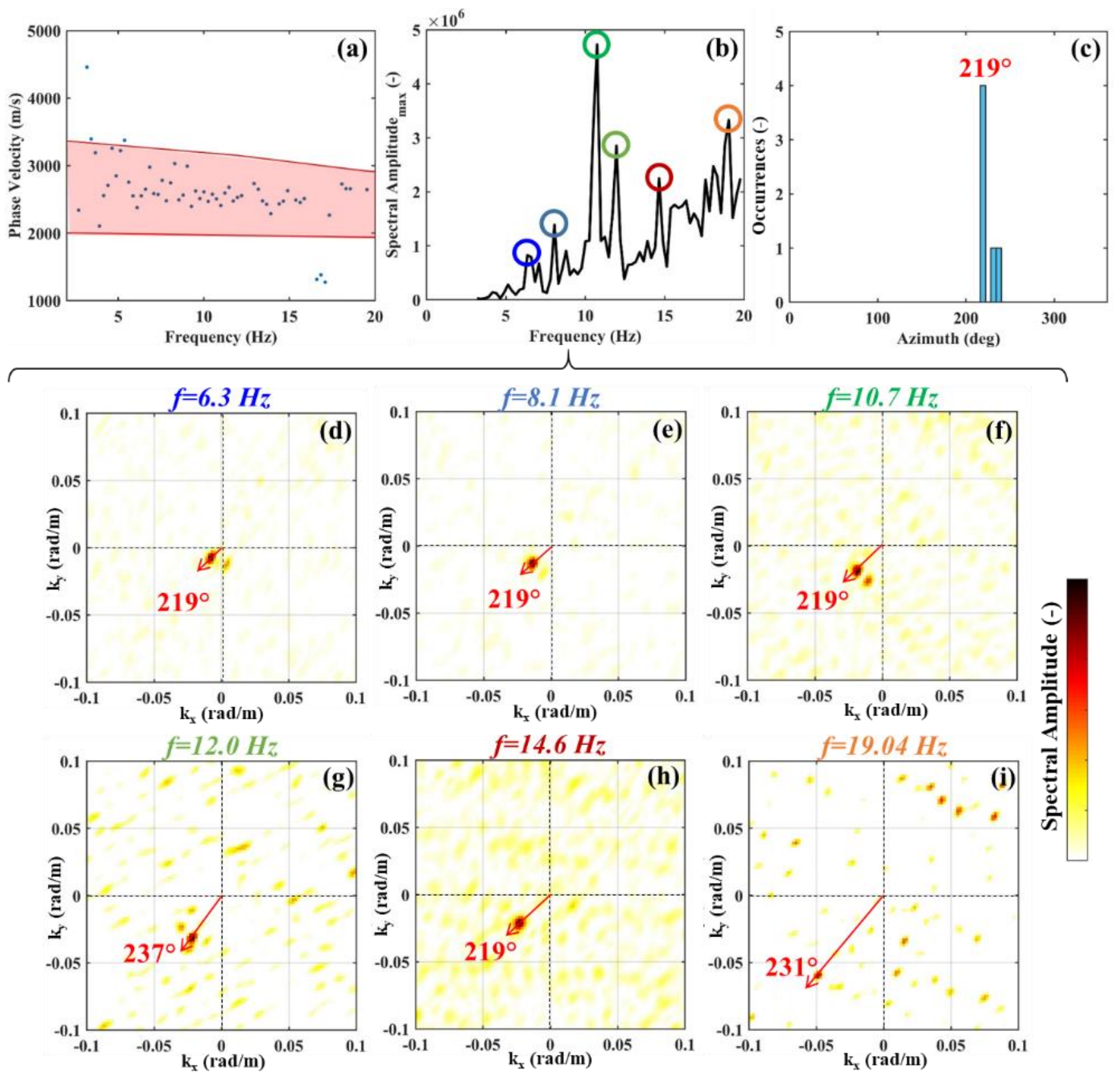

Figure 3: Example of FDBF computation on a 2-s window. (a) DC from the FDBF method compared to the reference dispersion region (in red, from active dispersion data, Da Col et al., 2020). (b) Spectral amplitude of the maxima in the $k_{x}-k_{y}$ planes (related to different frequencies). Coloured circles refer to the peak whose $k_{x}-k_{y}$ planes are shown in (d) to (i). (c) Histogram of the azimuth occurrences in the analyzed $k_{x}-k_{y}$ planes. (d) to (i) $k_{x}-k_{y}$ planes at different frequencies with azimuth computations (degrees counterclockwise from $E$, green reference system in Fig. 1d). 
https://doi.org/10.5194/se-2021-121

Preprint. Discussion started: 1 October 2021

(c) Author(s) 2021. CC BY 4.0 License.
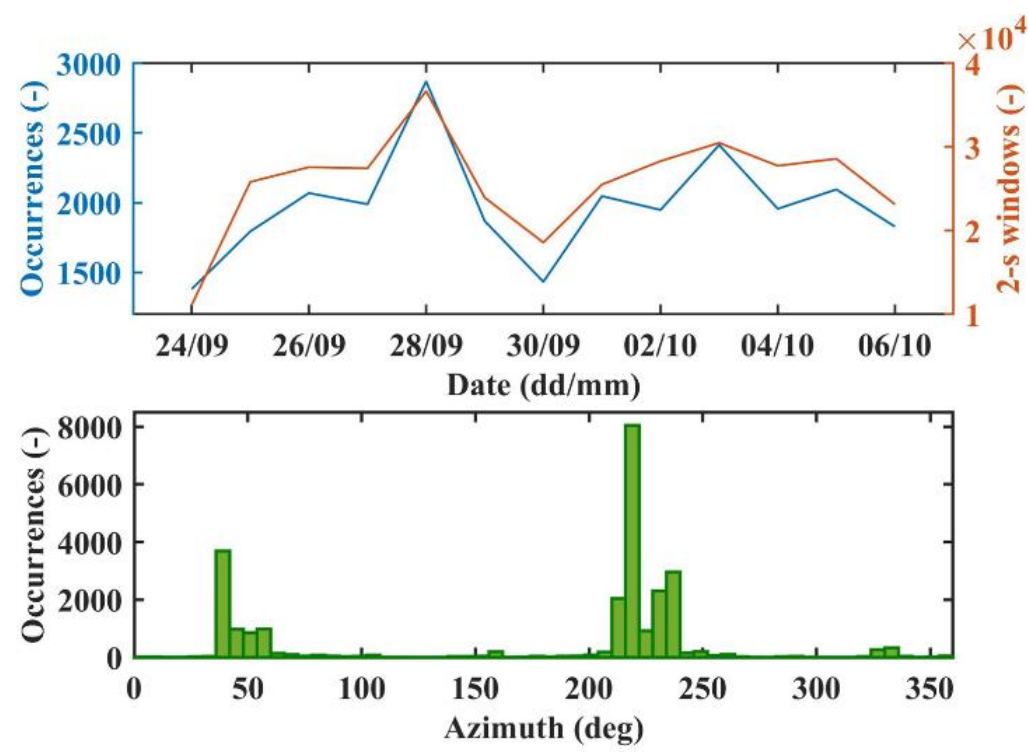

Figure 4: (a) Number of 2-s windows with strong SW content (in blue) and total number of 2-s windows recorded during each day of the survey (in orange). (b) Histogram of the azimuthal directions of the selected windows retrieved from the FDBF method (degrees counterclockwise from E, green reference system in Fig. 1d).
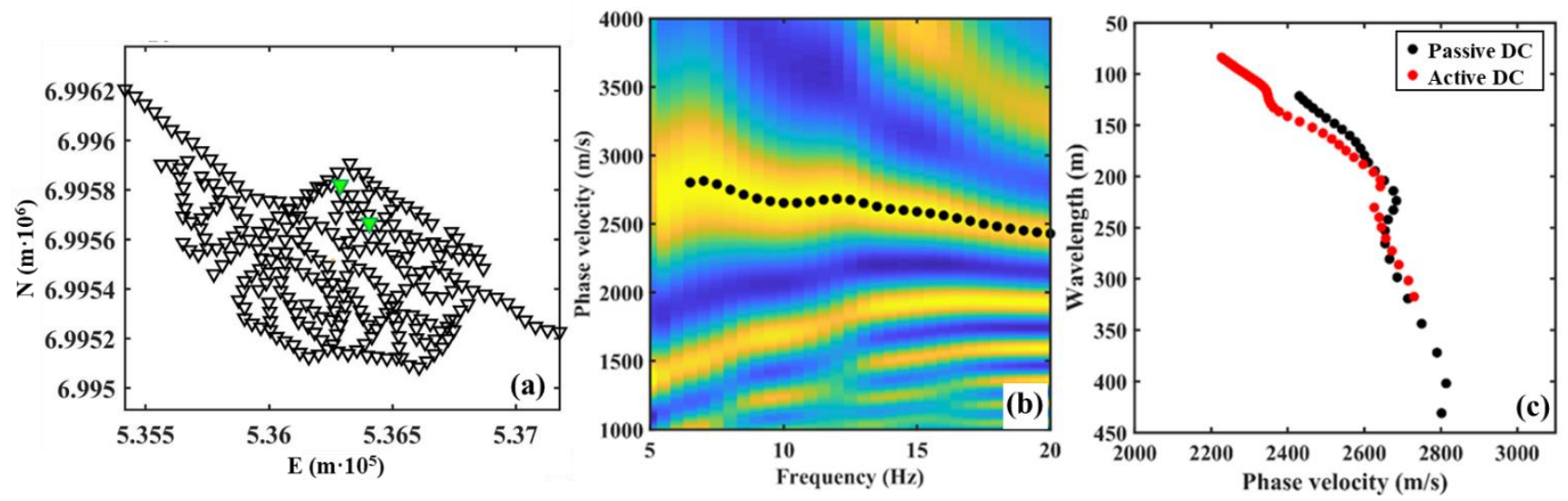

Figure 5: Example of DCs obtained by the two-station method. (a) Network geometry and considered receiver pair (green triangles). (b) Stacked cross-multiplication matrix and picked DC (black dots). (c) Comparison between passive and active DCs for the same receiver couple. 
https://doi.org/10.5194/se-2021-121

Preprint. Discussion started: 1 October 2021

(c) Author(s) 2021. CC BY 4.0 License.
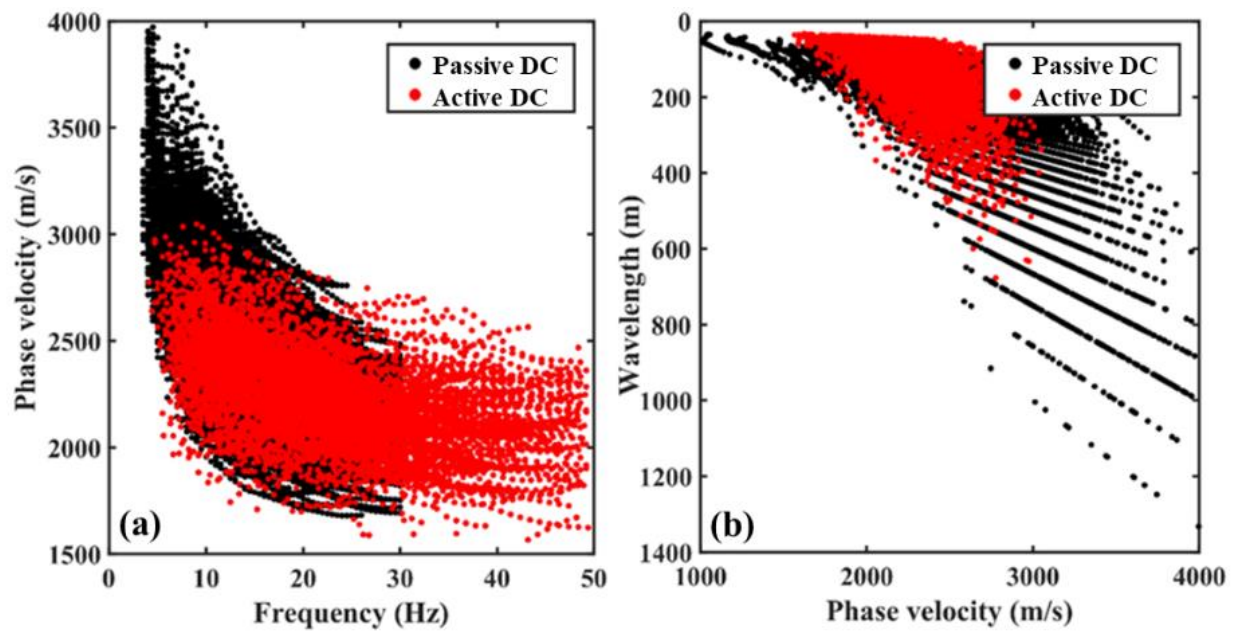

Figure 6: Passive (black) and active (red) dispersion curves. (a) Frequency-phase velocity domain. (b) Wavelength-phase velocity domain.
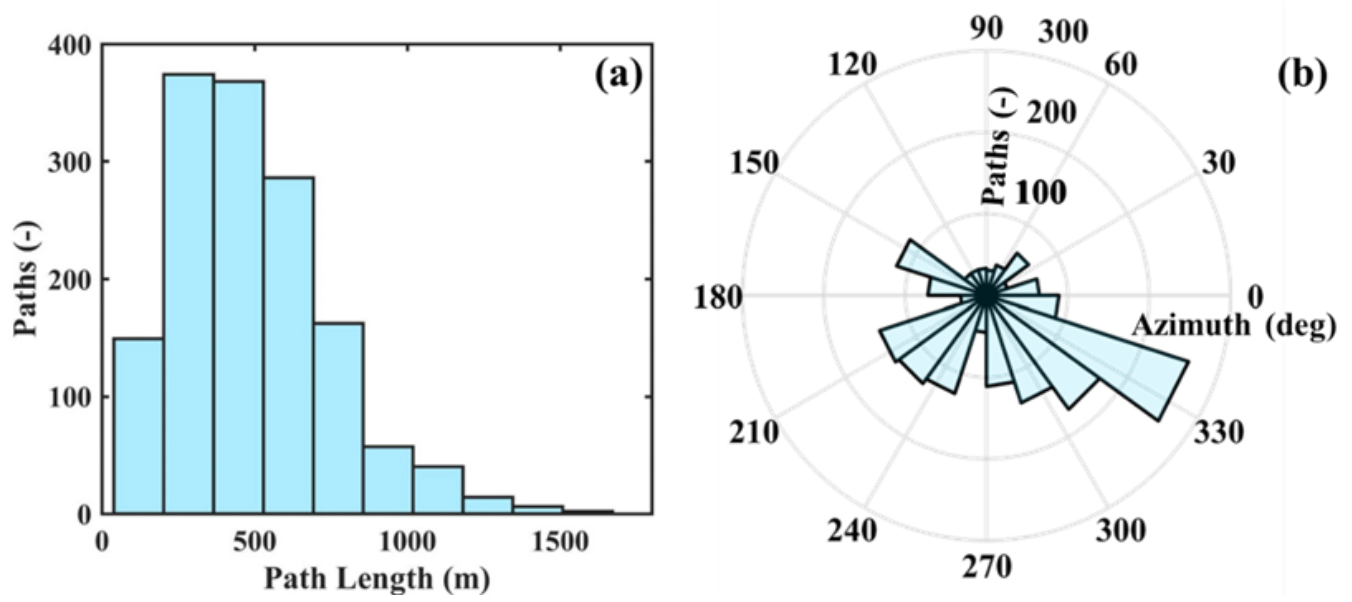

Figure 7: (a) Path length and (b) azimuth distribution of active+passive DCs. 
https://doi.org/10.5194/se-2021-121

Preprint. Discussion started: 1 October 2021

(c) Author(s) 2021. CC BY 4.0 License.
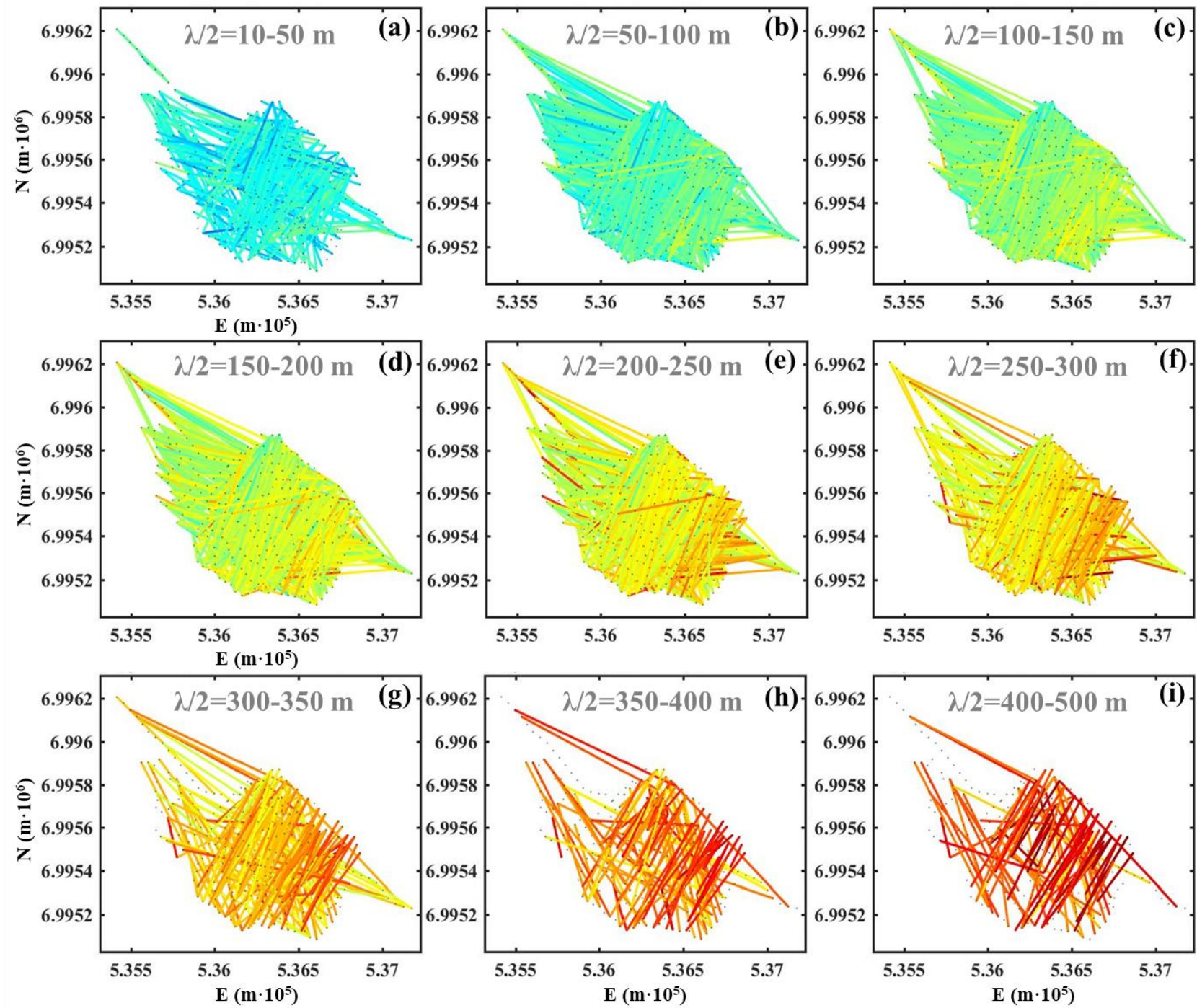

Apparent Rayleigh Velocity (m/s)

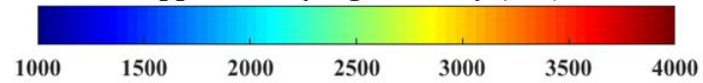

350 Figure 8: Tomographic pseudoslices at selected half-wavelength (pseudodepth) intervals. (a) 10-50 m, (b) 50-100 m, (c) 100-150 m, (d) 150-200 m, (e) 200-250 m, (f) 250-300 m, (g) 300-350 m, (h) 350-400 m, (i) 400-500 m. 

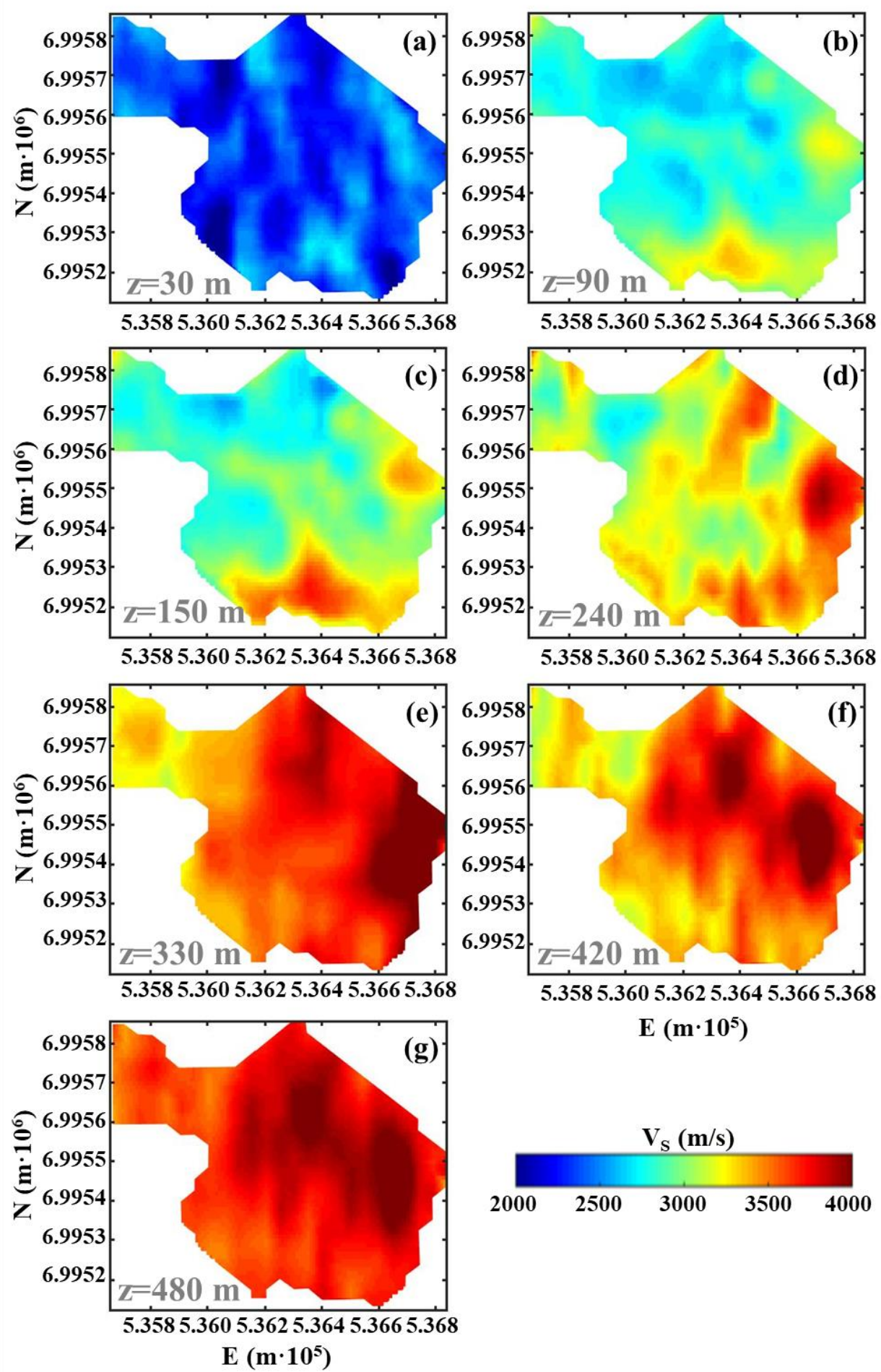

Figure 9: Final shear-wave velocity model obtained from active + passive SWT. Model slices at increasing depth: (a) 30 m, (b) 90 m, (c) $150 \mathrm{~m}$, , (d) $240 \mathrm{~m}$, (e) $330 \mathrm{~m}$, (f) $420 \mathrm{~m}$, , (g) $480 \mathrm{~m}$. 
https://doi.org/10.5194/se-2021-121

Preprint. Discussion started: 1 October 2021

(c) Author(s) 2021. CC BY 4.0 License.

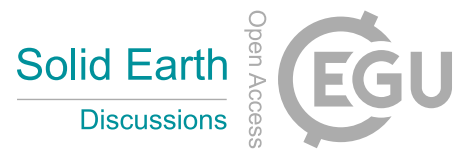

355
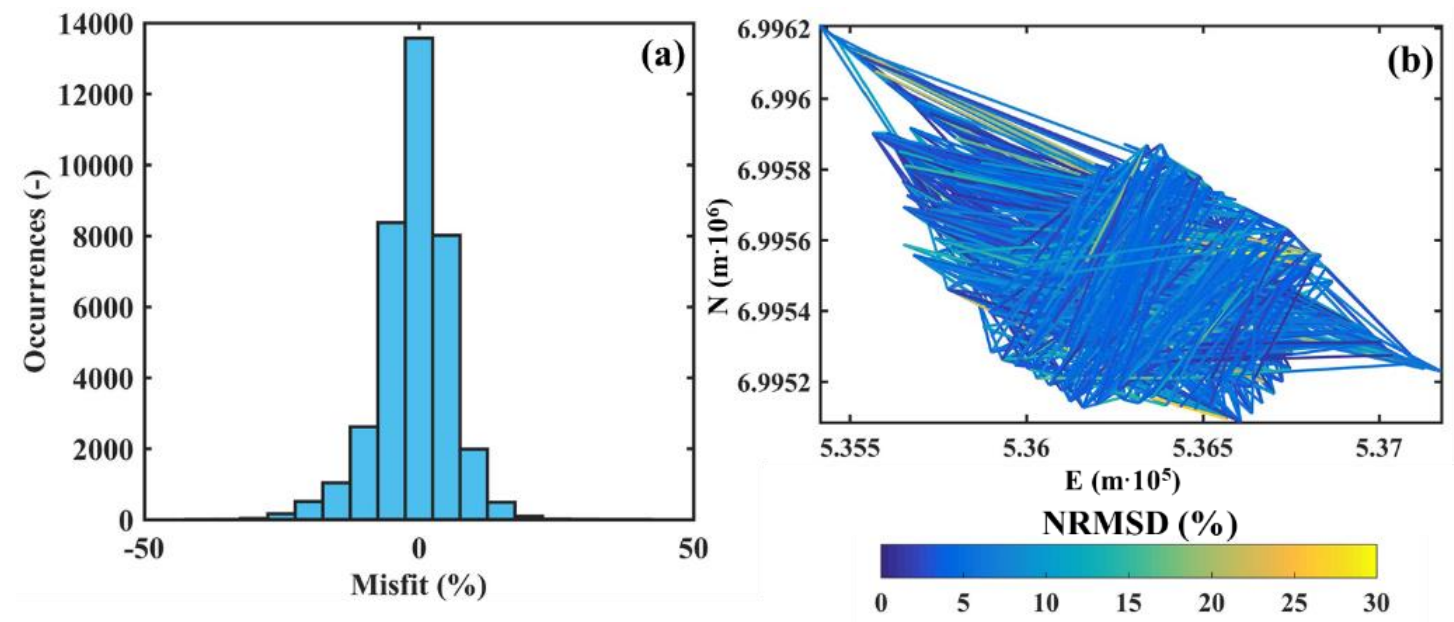

Figure 10: Misfit of the active+passive final inversion model. (a) Misfit (in percentage) for each experimental-calculated DC data point. (b) Map of the Normalized Root Mean Square Deviation of the DCs along the analyzed two-station paths. 


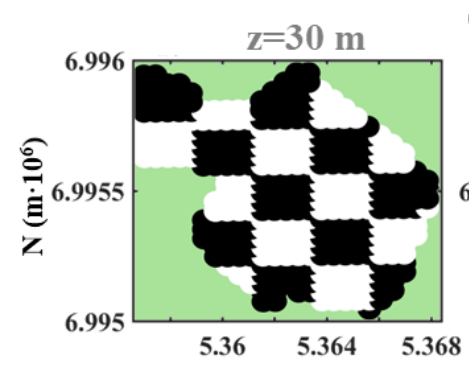

(a)
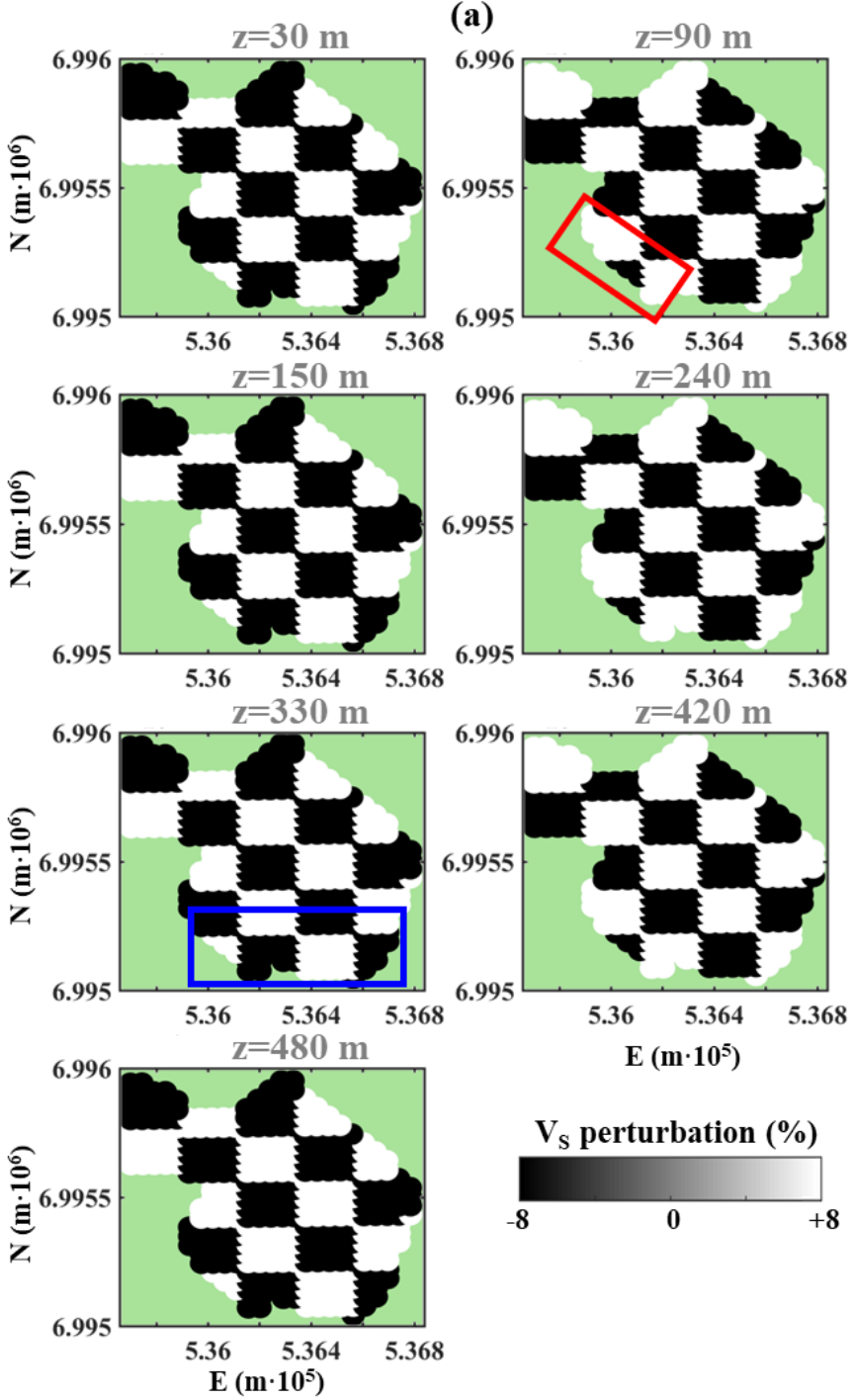
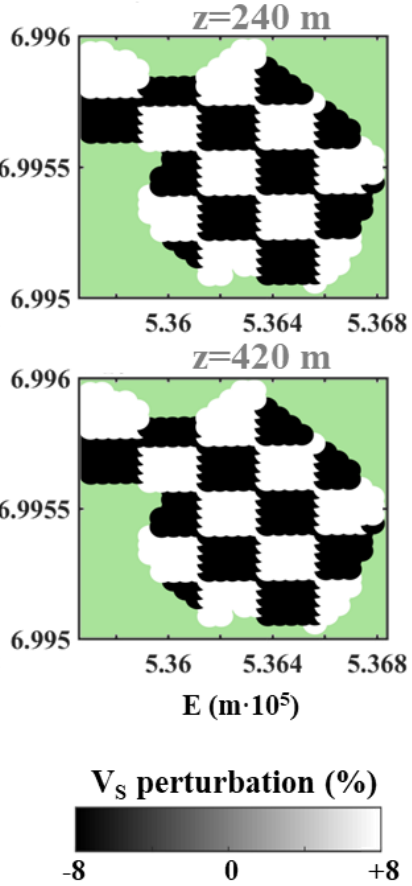

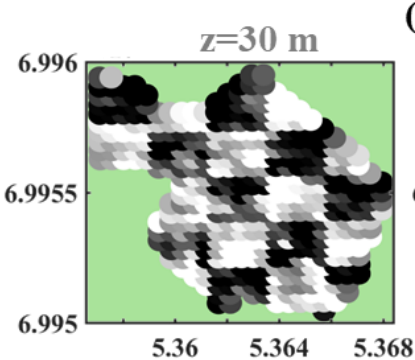

(b)
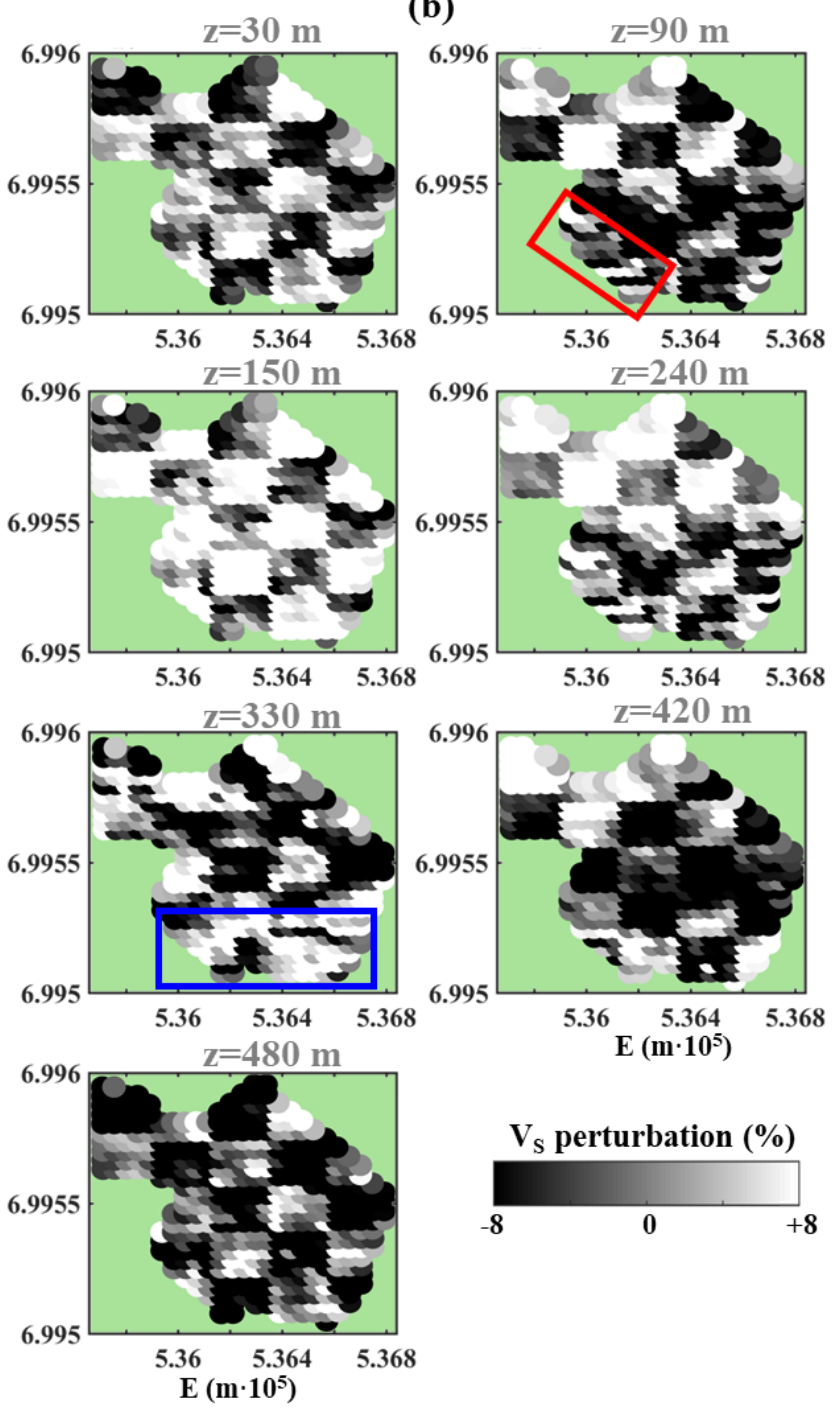

360 Figure 11: (a) True and (b) inverted checkerboard velocity perturbation. The boxes indicate velocity perturbations which could not be accurately recovered. 
b)

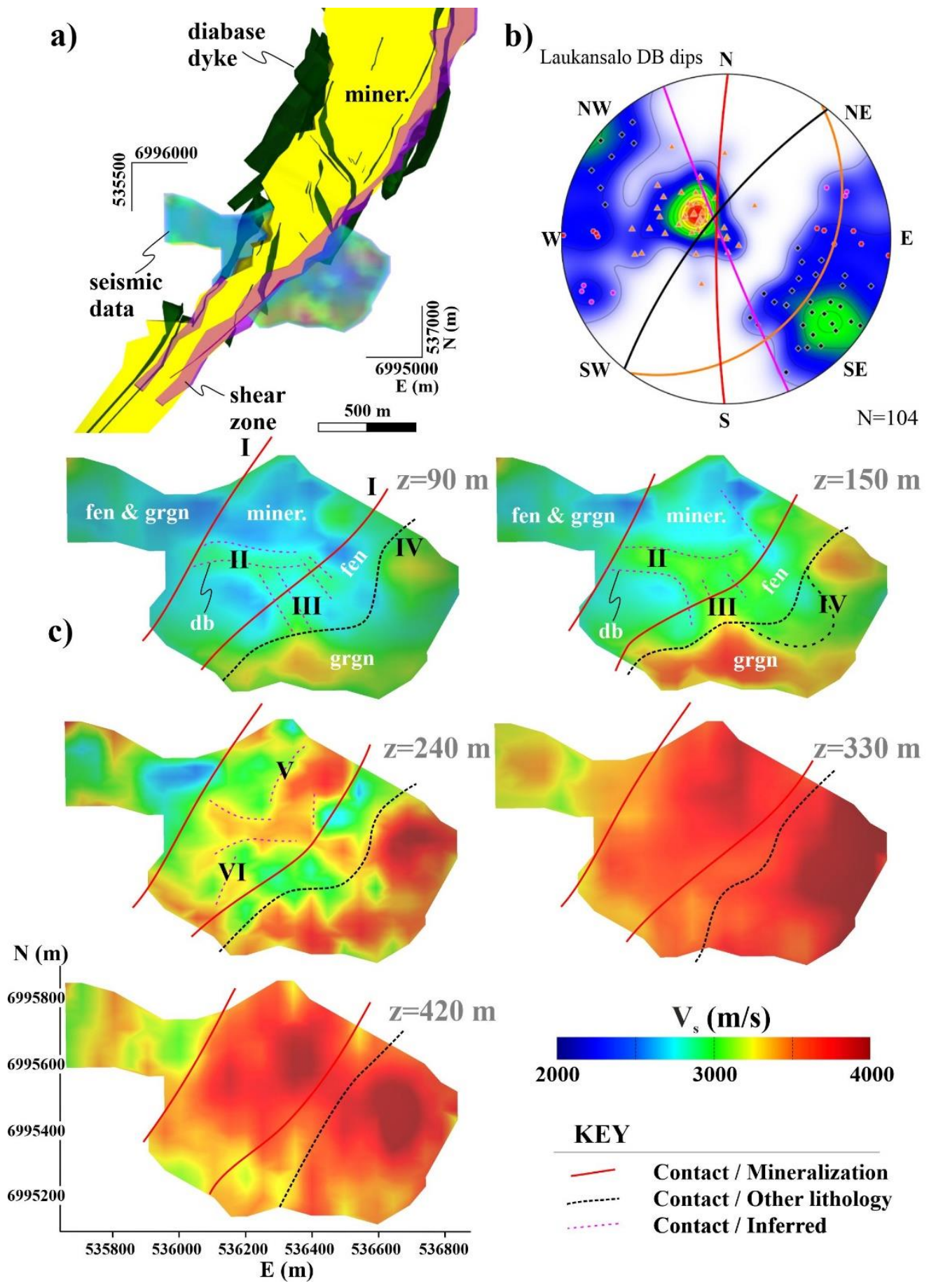

Figure 12: Geological interpretation of the final S-wave velocity model. (a) Overview of the area of the seismic investigation and the geological model of the site (from Yara). (b) Lower hemisphere stereographic projection of poles to the diabase contacts available from oriented diamond drill hole data. The great circles represent mean orientations of the four recognized diabase dyke sets. (c) Level images of the seismic data with geological interpretation of the main lithological boundaries. miner.=carbonatite-glimmerite mineralization, fen=fenite, $\mathrm{db}=$ diabase and grgn=granite-gneiss. 
https://doi.org/10.5194/se-2021-121

Preprint. Discussion started: 1 October 2021

(C) Author(s) 2021. CC BY 4.0 License.

sold Eant EG EGU

Table 1: Discretization and properties of the initial model of the tomographic inversion.

\begin{tabular}{ccccc}
\hline Layer & Thickness $(\mathrm{m})$ & $\mathrm{V}_{\mathrm{S}}(\mathrm{m} / \mathrm{s})$ & Density $\left(\mathrm{kg} / \mathrm{m}^{3}\right)$ & Poisson ratio $(-)$ \\
\hline 1 & 30 & 2200 & 2700 & 0.27 \\
2 & 60 & 2300 & 2700 & 0.27 \\
3 & 60 & 2400 & 2700 & 0.27 \\
4 & 60 & 2600 & 2700 & 0.25 \\
5 & 60 & 2800 & 2700 & 0.25 \\
6 & 60 & 3000 & 2700 & 0.25 \\
7 & 60 & 3200 & 2700 & 0.25 \\
Half-space & - & 3500 & 2700 & 0.25 \\
\hline
\end{tabular}

